\title{
TOTAL WASTE HEAT RECOVERY DEVICE FOR OFF-GAS FROM EAF*
}

Dong Maolin ${ }^{1}$ Zhou Tao $^{2}$

\begin{abstract}
Resumo
A great amount of high temperature off-gas, whose maximum temperature is up to $2100^{\circ} \mathrm{C}$, is generated during the smelting process of electric arc furnace (EAF). The dust content, which is mainly iron oxide, of the off-gas is high and worthy of industrial recovery. The heat carried by the high temperature off-gas with dust is about $11 \%$ of the total energy input of EAF, and some even is as high as $20 \%$. The high-temperature off-gas not only takes away a lot of heat but also places a huge burden to de-dusting system of EAF. It not only reduces the iron oxide dust recovery ratio, but also causes serious pollution problems. With the development of the iron and steel industry, the proportion of molten iron for EAF gradually increases, and even more than $30 \%$ in some cases. The increase of molten iron causes increases in the amount of EAF off-gas and heat waste. As a result the problem of dust removal is worsening ${ }^{[1-2]}$. How to sufficiently recover the sensible heat of the high temperature off-gas, create conditions for efficient dust removal, thus reduce operating costs of dust removal system and the production costs is a problem which EAF steel making companies must pay attention to.
\end{abstract}

Palavras-chave: Electric arc furnace, waste heat, sedimentation efficiency.

\section{TOTAL WASTE HEAT RECOVERY DEVICE FOR OFF-GAS FROM EAF}

\begin{abstract}
A great amount of high temperature off-gas, whose maximum temperature is up to $2100^{\circ} \mathrm{C}$, is generated during the smelting process of electric arc furnace (EAF). The dust content, which is mainly iron oxide, of the off-gas is high and worthy of industrial recovery. The heat carried by the high temperature off-gas with dust is about $11 \%$ of the total energy input of EAF, and some even is as high as $20 \%$. The high-temperature off-gas not only takes away a lot of heat but also places a huge burden to de-dusting system of EAF. It not only reduces the iron oxide dust recovery ratio, but also causes serious pollution problems. With the development of the iron and steel industry, the proportion of molten iron for EAF gradually increases, and even more than $30 \%$ in some cases. The increase of molten iron causes increases in the amount of EAF off-gas and heat waste. As a result the problem of dust removal is worsening ${ }^{[1-2]}$. How to sufficiently recover the sensible heat of the high temperature off-gas, create conditions for efficient dust removal, thus reduce operating costs of dust removal system and the production costs is a problem which EAF steel making companies must pay attention to..
\end{abstract}

Keywords: Electric arc furnace, waste heat, sedimentation efficiency.

CISDI Research \& Development Co., Ltd., Chongqing 401122, China. CISDI Research \& Development Co., Ltd., Chongqing 401122, China. 


\section{ADVANTAGES OF TOTAL WASTE HEAT RECOVERY DEVICE FOR OFF-GAS FROM EAF}

\subsection{Total Waste Heat Recovery}

The flow diagram of total waste heat recovery device is shown in Figure 1. This device uses high and low pressure combined cooling cycle, recovers $2100^{\circ} \mathrm{C} \sim 250^{\circ} \mathrm{C}$ total waste heat of off-gas from the EAF fourth hole.

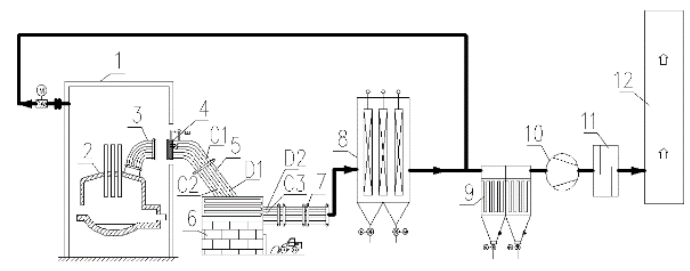

1. Dog house; 2. EAF; 3. Water-cooling elbow for fourth hole; 4 . Water cooling sleeve; 5 . Evaporative cooling inlet bend flue; 6. BSC; 7. Evaporative cooling outlet flue; 8. Tube waste heat boiler; 9 . Bag dust filter;

10.ID fan; 11. Silencer; 12. Chimney

Figure 1 Flow diagram of Total Waste Heat Recovery device

Primary gas from the EAF 2 mixes with the air drawn from the gap between the Watercooling elbow for fourth hole 3 and Water-cooling sleeve 4, enters evaporative cooling bend 5. After preliminary cooling in the evaporative cooling bend, the off-gas enters BSC 6. The upper half of the BSC adopts evaporative cooling structure. In the BSC, remained $\mathrm{CO}$ of the off-gas burns completely and large particles of the dust carried with off-gas settle by gravity meanwhile. The off-gas enters the high-pressure evaporative cooling flue 7 and tube waste heat boiler 8 to be further cooled. After being cooled to below $250{ }^{\circ} \mathrm{C}$ the off -gas mixes with fume from dog house 1 , and then enters bag dust filter 9 to de-dust. Subsequently the off-gas flows through ID fan 10, silenser11 and exhausts from the chimney when the dust content of the Off-gas reaches the required standard.

This device fully recovers the waste heat of off-gas from water cooling sleeve to tube waste heat boiler. By using natural circulation tube waste heat boiler, forced water flow is severely reduced and energy is saved compared with water-cooling system.

\subsection{Proper excess air coefficient}

EAF off-gas contains certain content of $\mathrm{CO}$. As the $\mathrm{CO}$ content is below the lower limit for gas recovery, secondary combustion technology is generally used to recover the latent heat of $\mathrm{CO}$ rather than recovering $\mathrm{CO}$ directly. Although in some projects a great amount of hot metal is added to EAF and $\mathrm{CO}$ concentration significantly increases, the process that $\mathrm{CO}$ is burned will not change because the advantages of EAF are located in short steel-making processes. Under such situation, it is particularly important to reasonably control the volume of mixed air for EAF waste heat boiler system and ensure the burnout of $\mathrm{CO}$ while keeping the thermal efficiency of waste heat boiler as high as possible. 
The combustion of EAF off-gas can be considered that $\mathrm{CO}$ and little $\mathrm{H}_{2}$ violently combine with oxygen in the air at high temperature, and a large amount of heat is given off during the process. To grantee the completeness of combustion, high temperature and adequate oxygen should be ensured, meanwhile the off-gas and oxygen should be well mixed. During the operation of EAF waste heat boiler, the impact of excess air coefficient on thermal efficiency of boiler cannot be ignored. Air shortage causes the incomplete combustion of off-gas and makes pollution when the off-gas emits to the atmosphere. On the contrary, excessive air will reduce the inlet temperature of off-gas and reduce the amount of waste heat recovered. As a result, exhausting heat losses will increase and boiler efficiency will be reduced, energy consumption of the ID fan will be increased. Therefore, it is necessary to determine an optimal excess air coefficient $\alpha$ to reach the minimum of heat loss and maximum heat efficiency of EAF waste heat boiler system.

During the smelting process of EAF, the main source of oxygen which involves in offgas combustion comes from three parts. One part comes from the blowing oxygen for smelting. Another part comes from the leaking air from the observation hole and electrode hole of EAF, etc. The third part comes from the air which enters from the water-cooling sleeve and is used to ensure the burnout of $\mathrm{CO}$. Only by reasonably controlling the opening of the water cooling sleeve based on the content of the off gas at the outlet of the BSC, the actual operational excess air coefficient can be close to the theoretical optimum value.

\subsection{High sedimentation efficiency}

The BSC has three main functions:

1) Heating off-gas at the initial stage of smelting and promoting $\mathrm{CO}$ combustion;

2) Promoting mixing of off-gas and air to ensure burnout of $\mathrm{CO}$ and other combustible ingredients;

3) Roughly de-dusting EAF off-gas and reducing dust entering the waste heat boiler to guarantee heat transfer efficiency and life span of it.

During the EAF smelting process, the temperature and composition of off-gas are changing with time. The main combustible ingredient of EAF off-gas is $\mathrm{CO}$. The ignition point of $\mathrm{CO}$ in the air is about $610^{\circ} \mathrm{C}$. I.e., only when the temperature of the mixture of $\mathrm{CO}$ and air exceeds $610^{\circ} \mathrm{C}$, the combustion of $\mathrm{CO}$ can be ensured in the BSC. Michio Nakayama etc. measured the composition and temperature of off-gas at the molting stage and the oxidizing stage of a 100t EAF ${ }^{[7]}$. The result shows as in Figure 2 and 3 that the composition and temperature of off-gas are different at different smelting stages of EAF.

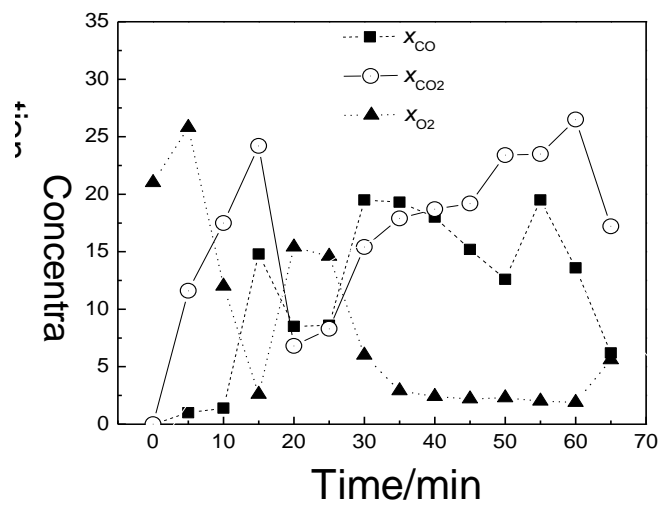

Figure 2 Composition of EAF off-gas 
The off-gas's temperatures at outlet of the EAF lid and at the outlet of BSC are measured When the composition of the primary off-gas are measured. Results are shown in Figure 3. T1 is the temperature of off-gas at the outlet of lid. T2 is the temperature at the outlet of the BSC. T3 is the theoretic temperature at the outlet of BSC based on the heat balance calculation.

As shown in Figure 2 and 3 , during the first 5 minutes of smelting process, the off-gas contains $\mathrm{CO}$ and the off-gas temperature does not reach the ignition point of $\mathrm{CO}$. Accumulated heat in the BSC has the function of heating EAF off-gas and increasing the temperature of the mixture of EAF off-gas and air, which is beneficial to burnout of CO.

Effective sedimentation of dust can guarantee the heat exchange efficiency of the following convection heating surface waste heat boiler and reduce the abrasion on the boiler surface. Therefore, effective sedimentation in the BSC should be achieved. Based on numerical simulation results, high efficient BSC is developed according to the concentration and particle size of dust in EAF off-gas and the mechanism of sedimentation.

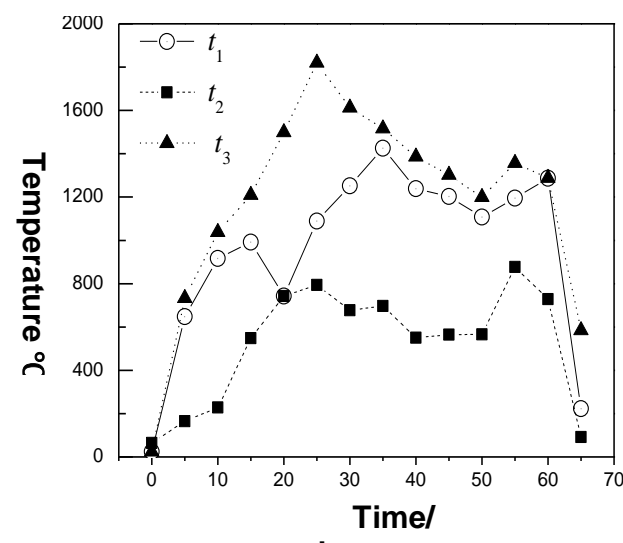

Figure 3 Temperature of EAF off-gas

\subsection{High pressure \& long life span boiler}

In order to avoid defects of heat pipe waste heat boiler mentioned in this article 1.2, tube waste heat boiler is adopted in total waste heat recovery device. Tube waste heat boiler not only improves the life span of the convection heating surface waste heat boiler, extends the failure time of the boiler, but also improves the steam pressure out of the steam drum. Meanwhile, in order to reduce investment and operating costs, the temperature of the off-gas at the inlet of tube waste heat boiler is controlled to below $1000^{\circ} \mathrm{C}$ and natural circulation is adopted.

\section{DEMONSTRATION PROJECT}

\subsection{Parameter Description}

Based on the above-mentioned advantages of the total waste heat recovery device, a demonstration project was designed and built. Onsite test was carried out on an $110 \mathrm{t}$ EAF in Yong Steel as well. Operating parameters are shown in Table 1. 
Table 1 Parameters of total waste heat recovery device for EAF in Yong Steel

\begin{tabular}{|c|c|c|}
\hline & ame & Parameters \\
\hline \multirow{5}{*}{ EAF } & Nominal capacity & $110 \mathrm{t}$ \\
\hline & Average steel output & $110 \mathrm{t}$ \\
\hline & EAF type & UHP AC, EBT \\
\hline & Blowing oxygen flow & $\begin{array}{l}\text { Average: } 7900 \mathrm{Nm}^{3} / \mathrm{h} \\
\text { Max: } 14500 \mathrm{Nm}^{3} / \mathrm{h}\end{array}$ \\
\hline & Average smelting period & $\begin{array}{c}42 \min (35 \% \text { Hot metal + Scrap) } \\
52 \mathrm{~min}(100 \% \text { Scrap })\end{array}$ \\
\hline \multirow{5}{*}{ Evaporative cooling system } & Inlet off-gas temperature & $300 \sim 2200^{\circ} \mathrm{C}$ \\
\hline & outlet off-gas temperature & $\sim 200^{\circ} \mathrm{C}$ \\
\hline & Working pressure of steam drum & $1.8 \sim 3.0 \mathrm{MPa}$ \\
\hline & \multirow{2}{*}{ Average steam production } & $25 \mathrm{t} / \mathrm{h}(35 \%$ Hot metal + Scrap $)$ \\
\hline & & 18t/h (100\% Scrap) \\
\hline
\end{tabular}

\subsection{Onsite test results}

1) off-gas temperature at the outlet of total waste heat recovery device.

Figure 5 shows the off-gas temperature curve at the outlet of tube waste heat boiler when the hot metal ratio is $35 \%$. The curve shows that the off-gas temperature fluctuates between $150 \sim 240^{\circ} \mathrm{C}$ in a typical smelting period.

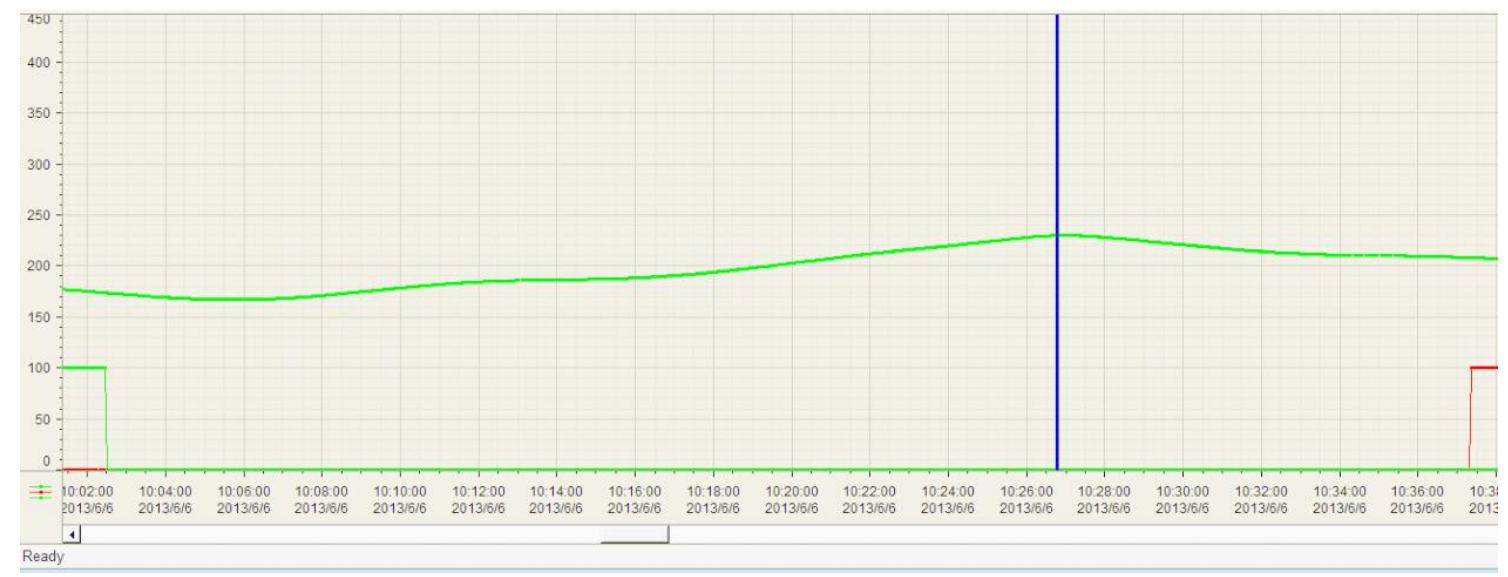

Figure 4 Outlet temperature of tube waste heat boiler

2) Sedimentation Efficiency

Dust concentrations at the inlet and outlet of BSC are tested onsite to verify the dedusting efficiency of the BSC.

There are two test points D1 and D2 (as showed in figure 2) to measure the dust concentration. D1 is located at end of evaporative cooling inlet bend flue before the BSC. D2 is located at the inlet of evaporative cooling outlet flue.

Test results are shown in Figure 5 and Figure 6 . Figure 5 is the dust concentration test results of total 9 heats at D1. Figure 7 is dust concentration test results of total 6 heats at D2. 


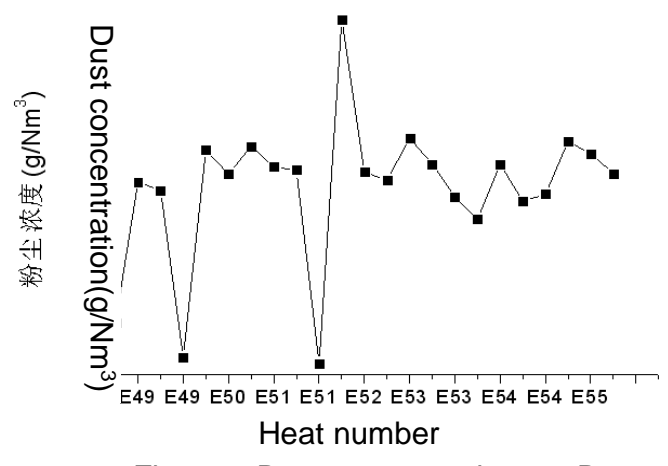

Figure 5 Dust concentrations at D1

By averaging the inlet and the outlet dust concentration of the BSC, it can be concluded that during the smelting period, the inlet dust concentration is $8.283 \mathrm{~g} / \mathrm{Nm}^{3}$, outlet dust concentration is $0.457 \mathrm{~g} / \mathrm{Nm}^{3}$.

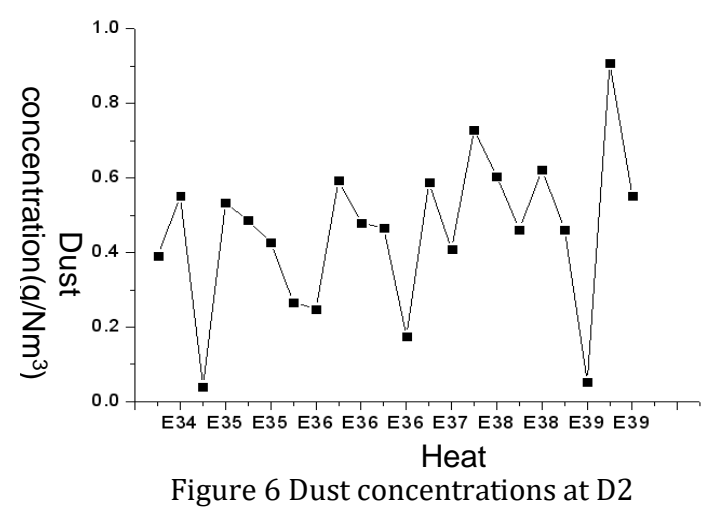

So the sedimentation efficiency in the BSC is:

$\eta=\left(1-\frac{C_{\text {out }}}{C_{\text {in }}}\right) \times 100 \%$

$=(1-0.457 / 8.283) \times 100 \%$

$=94.5 \%$

$\mathrm{C}_{\text {in }}$-Dust concentration at the inlet of BSC

Cout Dust concentration at the outlet of BSC

So nearly $94 \%$ of the dust in the off-gas is removed in the BSC.

\subsection{Excess air coefficient}

Off-gas compositions are measured at three points, which are located at middle of the evaporative cooling inlet bend flue (C1), at the inlet and outlet of the BSC (C2, C3) respectively. By calculating the composition of off-gas, it is concluded that the excess air coefficient $\alpha=2.1$ during the smelting period. After analysis, the reason is that the air participating in combustion is considered as the only part which enters from the gap of water-cooling sleeve in original design. However, it is discovered that a large amount of air participating in combustion is leaked from the furnace door, lid gap, and electrode hole of EAF in commissioning. This part of air is heated in the EAF and participates in the combustion. This is why the actual excess air coefficient is larger than the design value. 


\section{CONCLUSIONS}

(1)Total waste heat recovery device, which adopts combined high and low pressure, natural and forced circulation Total waste heat recovery device, successfully recovers $2100^{\circ} \mathrm{C} \sim 250^{\circ} \mathrm{C}$ total waste heat of off-gas from the EAF fourth hole. Meanwhile the device reduces the temperature of off-gas. By mixing with flue gas from the dog house and the roof de-dusting hood, the off-gas temperature reaches about $80^{\circ} \mathrm{C}$, which is an ideal de-dusting temperature.

(2) Tube waste heat boiler is used to improve the outlet steam pressure and temperature of the total waste heat recovery device. This measure makes steam easier to use and avoids the disadvantages of heat pipe boiler that heat transfer efficiency decreases greatly and heat pipe boiler fails in short time.

(3)By numerical simulation and theoretical calculation, the flow field is relative uniform in the BSC and the measured de-dusting efficiency reaches about $94 \%$.

(4)During the whole smelting period of EAF, the flow rate and compositions of the primary gas vary greatly. When the optimal excess air coefficient is adopted, the flow rate of off-gas will fluctuate greatly. Therefore we recommend that the opening degree of the water-cooling sleeve should be adjusted according to the compositions of off-gas at the outlet of BSC.

(5) Because a large amount of air participating in combustion is leaked from the furnace door, lid gap and electrode hole of EAF, the temperature of this part of air should not be considered as environmental temperature. It should be considered that this part of air is heated in the EAF and the design of waste heat recovery system will be more reasonable in this way.

\section{REFERENCES}

[1] GaoHailin. Smoke features and collecting and cleaning measures in electric furnace steelmaking [J] Meteorology and Environment Vol.22 No.6 (2006.12): $61 \sim 64$

[2] Chengzhu Jing, Shi Guohua. The Domestic Development Trend of the Latest Electric Furnace Waste heat Recovery Technology. China Steel Conference Proceedings. Beijing, 2009:272

[3] Yang Zhenguo , Liu Qing, etc. Waste heat recovery with heat pipes in the modern electric arc furnace process [J]. Journal of University of Science and Technology Beijing, 2011, Vol.33 No.11 (2011.10):1288-1292

[4] Michio Nakayama, Hirotsugu Kubo. Progress of Emission Control System in Electric Arc Furnace Melt -shop s [ J ]. NKK Technical Review. No. 84 (2001):16 - 23 